\title{
Attraction Through Air Exerted by Unaggregated Cells on Aggregates of the Slime Mould Polysphondylium violaceum
}

\author{
By B. M. SHAFFER \\ Department of Zoology, University of Cambridge
}

(Received 25 March 1964)

\begin{abstract}
SUMMARY
In darkness the unitary, elongated aggregates, or grex, of Polysphondylium violaceum are strongly attracted through air to earlier stages of development, including pre-aggregation and feeding cells. Hence the factor responsible cannot be acrasin. This attraction is dominant over mutual grex repulsion. The significance of the response is obscure. Dictyostelium discoideum cells also attract $\boldsymbol{P}$. violaceum grex, but do not appear to attract culminating $D$. discoideum grex.
\end{abstract}

\section{INTRODUCTION}

During the vegetative phase, cells of the collective amoeba, or cellular slime mould, Polysphondylium violaceum, lead a solitary existence, feeding on bacteria. When the food is exhausted, the cells enter a brief pre-aggregation phase, and then some of them found aggregation centres, which attract the others chemotactically. An aggregation centre eventually elongates perpendicularly to the agar substratum to transform itself into a cylinder with a tapered tip. This body, which behaves as an individual, is called a grex (The word 'grex' is unchanged in the plural). It constructs an axial stalk, which it proceeds to climb, at the same time extending it at the tip. An increasing length of bare stalk is uncovered as the grex advances. Periodically, small masses of cells are cut off from the rear of the grex, and these produce whorls of short side branches that are roughly perpendicular to the main stalk (Harper, 1929). The following descriptions apply only to the main stalk; the branches are too short to respond strikingly.

I previously reported (1962) that when a large number of Polysphondylium violaceum cells were deposited in an area about $5 \mathrm{~mm}$. across in the middle of a culture plate, the grex they formed were initially more or less erect, but that soon the tips bent outwards while in mid-air, and predominantly without touching one another, so that the resultant fruiting bodies occupied a hemispherical air space, with their stalks projecting along the radii. Grex continued radially outwards even if they landed on the agar. When they were experimentally turned to point radially inwards, they soon made a $U$-turn to bring themselves back to their former orientation. When the cells were deposited close to the edge of the dish, most of the grex that formed nearest the glass side wall veered away from it without making contact with it; consequently a corridor next to the wall remained almost empty of fruiting bodies. Moreover, single isolated grex lying on the agar generally made a 
U-turn when they approached to within a millimetre or two of the glass wall. It was thought probable that the grex were reacting by negative chemotaxis to some aerial concentration gradient resulting from their own metabolism. Bonner \& Dodd $(\mathbf{1 9 6 2} b)$ had come to the same conclusion after a much more thorough investigation of the reaction of four other species of slime moulds to various foreign bodies and experimental procedures.

As there was already tolerably good evidence (Samuel, 1961; Shaffer, 1962) that the cells repelled one another during the vegetative and pre-aggregation stages, and that they continued to produce the repellent material during aggregation-though its action was then usually masked by that of the attractor, acrasin-it was simplest to suppose that the grex responded to the same repellent. Against this hypothesis, I pointed out that when Polysphondylium violaceum was inoculated in a limited region in the middle of a thick bacterial layer, the grex that formed in this region still bent outwards, despite their being surrounded by concentric zones of all stages from feeding to aggregation, and moreover that they might even land in these zones. However, it now appears that the basis of this response is quite different from what was supposed; its nature will now be described.

\section{METHODS}

The slime mould Polysphondylium violaceum was grown with Escherichia coli on half-strength Bonner's (1947) agar ( \%: 0.5, glucose; 0.5, peptone; 2, agar, phosphatebuffered at $\mathrm{pH}$ 6.8) in Petri dishes. To exclude orientation responses to light and temperature gradients, the cultures were kept in cardboard boxes in black envelopes in a drawer lined with expanded polystyrene.

\section{RESULTS}

When Escherichia coli was inoculated over the whole plate, and Polysphondylium violaceum at one side along the edge of it, a wave of feeding amoebae slowly advanced across the agar. Behind them there was always a zone of pre-aggregation cells, and then, at most times of day, zones of aggregations and grex. The final zone contained fruiting bodies. The first fruiting bodies to be formed were sited at the edge of the dish; these were very obviously oriented away from the glass, as expected, though most of them seemed to be too nearly horizontal for them to have been escaping from a high concentration of repellent that they had themselves produced. The fruiting bodies that formed later, in the middle of the dish, pointed in the same direction as the first ones, namely, in the direction in which the feeding cells were advancing, which we shall refer to as 'forward'. Although this orientation might have resulted because there had always been grex or older fruiting bodies behind them to repel them, this explanation became highly unlikely when it was appreciated that the fruiting bodies that formed on the far side of the dish still pointed forward, and therefore towards the glass side-wall, even when they were closer to it than individual isolated grex had been when they had turned away from it. The stalks formed up to this point were not distributed evenly through the available air space, but had a strong tendency to bend close to the agar surface. However, when the feeding cells had advanced to the edge of the plate and had consumed all the food, the fruiting bodies that these cells then formed did veer away from the glass. 
The next step was to remove all the pre-aggregation cells, aggregations, and grex present at a given moment when the feeding cells had eaten their way some distance across a plate. The first fruiting bodies to be built ahead of the empty swath still leaned forward very markedly, even though there were no grex behind them, or even any close fruiting bodies, that could have repelled them. There was therefore a strong suggestion that the grex were being attracted forwards. This was shown yet more convincingly by inoculating the slime mould at one end of a narrow bacterial streak. Had the orientation of the grex been dominated by their mutual repulsion, their stalks should have projected in planes perpendicular to the streak axis. In fact, the great majority of them pointed straight forwards along it-those formed in the mid-line of the streak pointing forwards soon after they rose from the agar, those nearer the edge first growing out slightly to the side and then turning forwards. In contrast, when the slime mould was initially inoculated along the whole length of the streak, the resultant stalks were distributed in planes transverse to the streak. It might therefore be concluded that when all the amoebae present were at the same stage of development, the orientation of the grex was greatly influenced by mutual repulsion; but that when grex developed close to bacteria and earlier stages of development, they were strongly attracted towards them, and that this attraction was dominant over repulsion.

This raised the question as to whether it was the bacteria or the amoebae that were attractive, and if the amoebae, at which stages. A strong hint as to the answer was given by the observation, already reported, that often the largest grex landed on the agar among the feeding and pre-aggregation cells. The reason why only the largest grex could make an actual landing was simply that only they made stalks long enough for them to arch over the intervening zone of aggregation. This behaviour had not previously seemed remarkable, for the following reasons. Newly formed grex of Dictyostelium discoideum usually migrate for some time over the agar surface, without constructing a stalk, before they become erect again and turn into stalked fruiting bodies (Raper, 1935). (This re-erection itself poses a problem in orientation, but we are not concerned with it here.) It has long been known that the stalked grex of other species, including Polysphondylium violaceum, may pass through a phase believed to be comparable with migration, in which they crawl on their sides over the agar surface (Raper, 1941). Also, since mutual repulsion may make the peripheral members of a stand of grex travel outwards at a rather oblique angle to the agar surface even during an aerial phase, and since long stalks when nearly horizontal are mechanically rather unstable, it might be expected that grex at the end of such stalks would tend to land on the agar. However, it was found during the present work that when the culture plate was incubated upside-down, the large grex still managed to land on the agar among the feeding and pre-aggregation cells. Clearly therefore the grex were not reacting to gravity but were being led towards these cells. The grex often buried themselves so deeply in the thick layer of feeding slimemould cells that they became virtually invisible, except for their cellulose stalks and extreme tips. Nevertheless, their development continued.

The reactions of the grex were examined by cutting out a rectangular block a few centimetres square from agar of standard thickness and bearing cells of any desired stage of development, and placing it alongside a block carrying a row of large aggregation centres. To prevent cells wandering from one block to the other, a strip of 
polystyrene film was inserted between them of such a height that it projected just above the agar surface. In this way, it was clearly shown that grex were strongly attracted to feeding cells as well as to pre-aggregation cells. Young aggregations seemed to be rather less attractive. However, although the different test blocks were taken from similar cultures, and therefore bore cells at approximately the same population density, no accurate comparison between these stages was attempted. The main object of these experiments was to determine whether or not the grex were attracted to amoebae that had not begun to aggregate. Plate 1, fig. 1, shows a simpler version of this demonstration: aggregating centres were merely deposited in a single line next to the edge of a band of feeding amoebae several centimetres wide.

A few similar experiments were performed with Dictyostelium discoideum. Carrying the aggregation centres through the air to deposit them in a line subjected them to sufficient desiccation to eliminate the migration phase, and the grex proceeded to culminate where they were deposited. The resultant fruiting bodies did not incline towards the adjacent band of feeding cells; on the contrary, in general they leant away from it (Pl. 1, fig. 2). But D. discoideum cells did attract grex of Polysphondylium violaceum.

The possibility that the bacteria used (Escherichia coli) were primarily responsible for the attraction had still not been completely excluded, although it seemed most unlikely, as there were virtually no uningested bacteria left between the pre-aggregation cells. Yet these cells did still contain some bacteria, and presumably smelt of the $E$. coli they had digested. Test blocks were therefore cut from plates inoculated solely with $E$. coli. These did not strikingly attract grex of Polysphondylium violaceum, although the experiments were not precise enough to show whether or not the bacteria were very weakly attractive.

On the basis of the above results, the following more striking method of showing the attraction was devised. A circular area about $1 \mathrm{~cm}$. in diameter was inoculated with Escherichia coli, and Polysphondylium violaceum spores were added all round the perimeter of this area. The amoebae ate their way inwards till they met in the middle. By the time grex had developed at the periphery, the middle was packed with amoebae that had completely or almost completely consumed the bacteria there, as shown by the increase in transparency. In these conditions, the grex oriented radially inwards (Pl. 1, fig. 3), and the end result was a tangle of fruiting bodies lying on the agar. In contrast, when the initial diameter of the inoculum was sufficiently small for there to be no unaggregated cells in the middle when the grex sprang up at the edge, these formed the usual graceful fruiting bodies, oriented radially outwards.

\section{DISCUSSION}

In Polysphondylium violaceum, the onset of aggregation is abrupt (Shaffer, 1961), and before that the amoebae do not release acrasin, at least in detectable amounts. It is therefore clear that grex are attracted to unaggregated cells by something other than acrasin. Although it seems probable that the effective agent in attraction is a gas or a volatile metabolite, no attempt has been made to demonstrate this directly. Bonner \& Dodd (1962b) conducted many experiments that tended to show that this was true of the factor by which the grex repelled one another, but they pointed out that conclusive evidence was still lacking. Since then, I have observed aerial grex 
responses to such a variety of distant materials that it has become still more improbable that there could be a purely physical explanation for all of them.

Bonner \& Dodd (1962b) showed that grex were strongly attracted towards activated charcoal, and they interpreted this to mean that the charcoal adsorbed the repellent, and hence that the grex responded to it by negative chemotaxis. So perhaps unaggregated cells are attractive because they efficiently absorb a repellent made by the grex. Yet this seems unlikely, for in the last experiment described, the grex crowded radially inwards to form almost a solid mass, instead of turning towards the rest of the culture plate which was completely unoccupied. In any case, if the individual cells repel one another, as some evidence suggests they do (Samuel, 1961; Shaffer, 1962), there must be at least two factors: either the grex make a different repellent; or they make the same repellent as the separate cells, and these cells must also make an attractor.

Bonner \& Hoffman (1963) believe that one and the same 'spacing substance' is responsible for mutual grex repulsion and for preventing too many aggregations from forming in a given area (Shaffer, 1962; Bonner \& Dodd, 1962 $a, b$ ). They found that the same factor was produced by all the species they tested, including Polysphondylium violaceum and Dictyostelium discoideum, but that at the aggregation stage $D$. discoideum was insensitive to it. By the grex stage, $D$. discoideum had become sensitive to it; that is to say, culminating Dictyostelium grex repelled one another and were also repelled by grex of Polysphondylium. In the present work it has been found that cells of both species can attract grex of $\boldsymbol{P}$. violaceum. However, culminating $D$. discoideum grex appear not to be attracted. Perhaps they are attracted covertly, but in the conditions used, repulsion is dominant. Certainly when attraction and repulsion occur simultaneously, the balance may be subtle, as I have elsewhere (1962) discussed with reference to aggregation.

Has grex attraction any adaptive value? Bonner \& Dodd (1962b) and Bonner \& Hoffman (1963) suggested that it is advantageous for the organism to space out its fruiting bodies, as well as its aggregations. The repulsion between individual feeding and pre-aggregation cells may also be interpreted as an adaptation to finding food. At first sight, this argument accords perfectly with the newly discovered phenomenon: the grex are attracted towards feeding cells. But this extension of the argument does not survive examination. The grex are not attracted strongly to food itself but to feeding cells, and to cells that have consumed all the available food. A more serious objection is that even if this response does sometimes lead a grex to food, it could be considered adaptive only if the grex could take advantage of the food it had found. In fact, although a very small proportion of the peripheral grex cells do return to the vegetative stage, a grex as a whole continues to develop into a fruiting body even when it has buried itself in the layer of feeding cells or of bacteria. Indeed, even if aggregated Polysphondylium violaceum cells are mechanically disaggregated in the presence of bacteria, most of them immediately reaggregate (Shaffer, 1961).

\section{REFERENCES}

Bonner, J. T. (1947). Evidence for the formation of cell aggregates by chemotaxis in the development of the slime mould Dictyostelium discoideum. J. exp. Zool. 106, 1.

BonNer, J. T. \& Dodd, M. R. (1962a). Aggregation territories in the cellular slime moulds. Biol. Bull. mar. biol. Lab., Woods Hole, 122, 13. 
BonNer, J. T. \& DodD, M. R. (1962b). Evidence for gas-induced orientation in the cellular slime molds. Devl. Biol. 5, 344.

Bonner, J. T. \& Hoffman, M. E. (1963). Evidence for a substance responsible for the spacing pattern of aggregation and fruiting in the cellular slime molds. J. Embryol. exp. Morph. 11, 571.

Harper, R. A. (1929). Morphogenesis in Polysphondylium. Bull. Torrey bot. Club, 56, 227.

RAPER, K. B. (1935). Dictyostelium discoideum, a new species of slime mold from decaying forest leaves. J. agric. Res. 55, 289.

RAPER, K. B. (1941). Developmental patterns in simple slime molds. Growth, 5, 41.

SAmuel, E. W. (1961). Orientation and rate of locomotion of individual amoebae in the life cycle of the cellular slime mold Dictyostelium discoideum. Deol. Biol. 3, 317.

Shaffer, B. M. (1961). The cells founding aggregation centres in the slime mould Polysphondylium violaceum. J. exp. Biol. 38, 833.

Shaffer, B. M. (1962). The Acrasina. Adv. Morphogen. 2, 109.

\section{EXPLANATION OF PLATE}

Fig. 1. Aggregation centres of Polysphondylium violaceum were deposited on the bare agar in a single row just beyond the edge of a broad band of homologous feeding cells. The resultant grex have all oriented in the dark towards the feeding cells, with the exception of the two smallest grex, one of which has arisen directly opposite a large one and may have been repelled by it.

Fig. 2. An experiment identical with that shown in fig. 1, except that the species is Dictyostelium discoideum. The bare agar (above) is covered with tracks produced by a very small number of separate cells. The fruiting bodies are more erect than those of the grex seen in fig. 1, but they lean predominantly away from the feeding cells.

Fig. 3. The great majority of $P$. violaceum grex that have formed around the periphery of a circular area of feeding cells have oriented almost radially inwards and are nearly horizontal. 


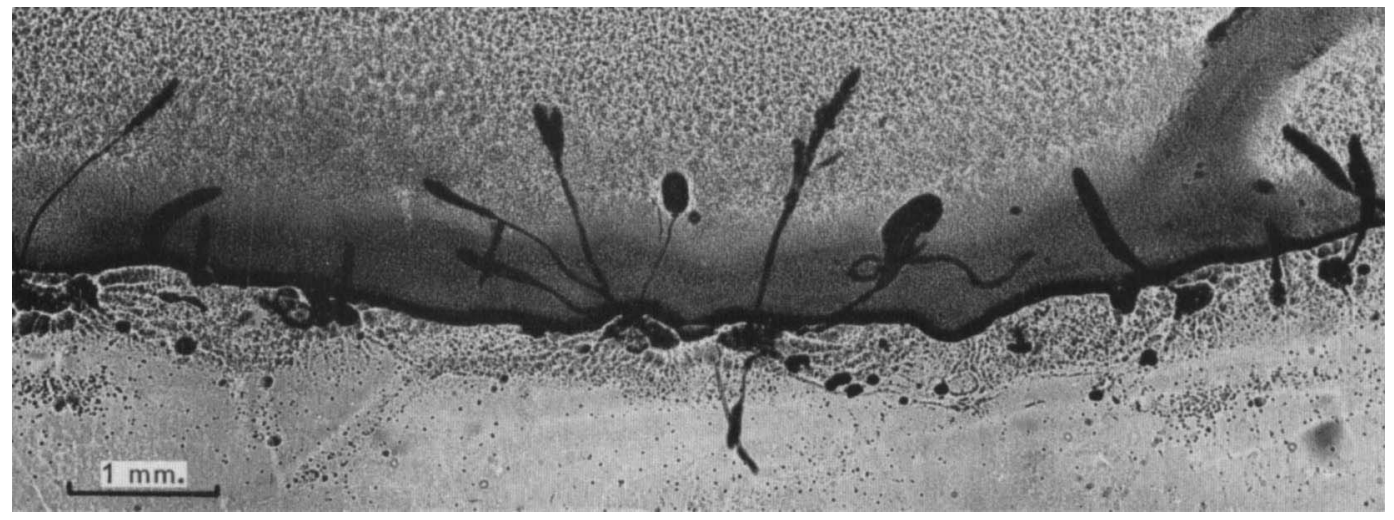

Fig. 1

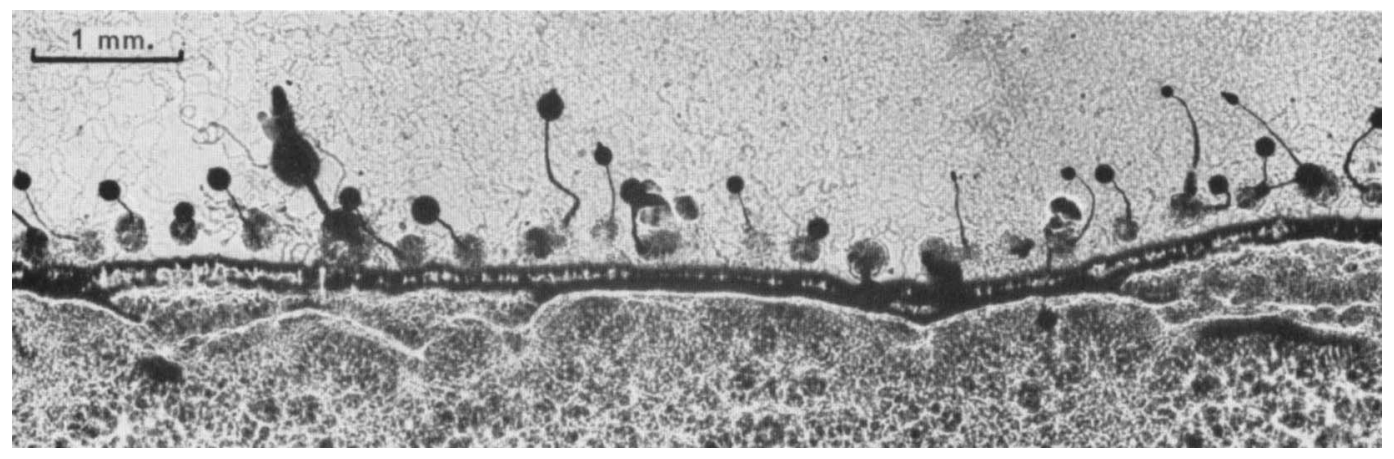

Fig. 2

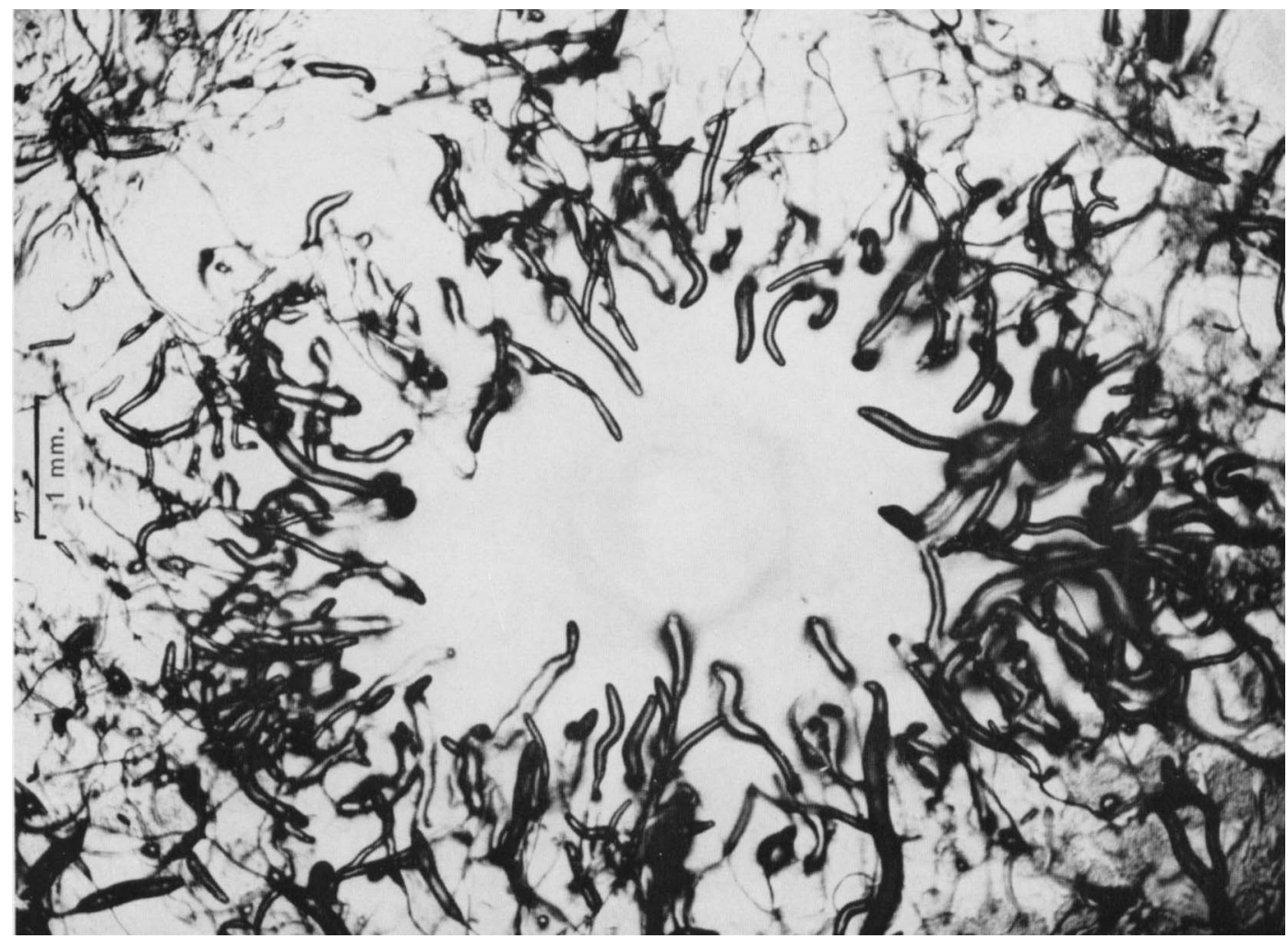

Fig. 3 